\title{
Recruitment of trimeric proliferating cell nuclear antigen by G1-phase cyclin-dependent kinases following DNA damage with platinum-based antitumour agents
}

\author{
$\mathrm{G} \mathrm{He}^{1}$, J Kuang ${ }^{1}$, J Koomen ${ }^{2}, \mathrm{R} \mathrm{Kobayashi}^{2}$, A R Khokhar ${ }^{1}$ and Z H Siddik ${ }^{\star}, 1$ \\ ${ }^{1}$ Department of Experimental Therapeutics, The University of Texas MD Anderson Cancer Center, Unit 1950, 1515 Holcombe \\ Boulevard, Houston, TX, USA and ${ }^{2}$ Department of Molecular Pathology, The University of Texas MD Anderson Cancer Center, \\ Houston, TX, USA
}

Background: In cycling tumour cells, the binary cyclin-dependent kinase Cdk4/cyclin D or Cdk2/cyclin E complex is inhibited by p21 following DNA damage to induce G1 cell-cycle arrest. However, it is not known whether other proteins are also recruited within Cdk complexes, or their role, and this was investigated.

Methods: Ovarian A2780 tumour cells were exposed to the platinum-based antitumour agent 1R,2R-diaminocyclohexane(transdiacetato)(dichloro)platinum(IV) (DAP), which preferentially induces G1 arrest in a p21-dependent manner. The Colk complexes were analysed by gel filtration chromatography, immunoblot and mass spectrometry.

Results: The active forms of Cdk4 and Cdk2 complexes in control tumour cells have a molecular size of $\sim 140 \mathrm{kDa}$, which increased to $\sim 290 \mathrm{kDa}$ when inhibited following G1 checkpoint activation by DAP. Proteomic analysis identified Cdk, cyclin, p21 and proliferating cell nuclear antigen (PCNA) in the inhibited complex, and biochemical studies provided unequivocal evidence that the increase in $\sim 150 \mathrm{kDa}$ of the inhibited complex is consistent with p21-dependent recruitment of PCNA as a trimer, likely bound to three molecules of p21. Although p21 alone was sufficient to inhibit the Cdk complex, PCNA was critical for stabilising p21.

Conclusion: G1 Cdk complexes inhibited by p21 also recruit PCNA, which inhibits degradation and, thereby, prolongs activity of p21 within the complex.

Slowdown or arrest of the cell cycle following DNA damage is a characteristic checkpoint response, which is a critical process that allows cells time to repair the DNA and avoid DNA replication or mitosis in the presence of damaged chromosomes. When DNA damage is excessive and repair incomplete, cells will activate the apoptotic cell death programme as a resultant outcome. This implies a link between checkpoint response and drug-induced cell death, and a strong correlation has indeed been demonstrated in the case of platinum-based drugs (Vekris et al, 2004). The tumour suppressor p53 has a central role in both DNA damage checkpoint response and apoptosis, but these functions generally require activation of $\mathrm{p} 53$, which then transactivates downstream genes for p53-dependent cellular effects. Activation of p53 by DNA damaging agents occurs following upregulation of discrete signal transduction pathways upstream and this is dependent on the type of DNA damage. Ionising radiation and doxorubicin, for instance, induce DNA strand breaks, which activate p53 via the ataxia telangiectasia mutated (ATM)-dependent pathway, whereas UV 
radiation and platinum-based cisplatin, on the other hand, induce in DNA the formation of cyclobutane pyrimidine dimers and intrastrand adducts, respectively, that activate p53 via the ataxia telangiectasia and Rad3-related (ATR)-dependent pathway (Siddik et al, 1998; Siddik, 2003). Irrespective of the type of DNA damage, a gene commonly transactivated by $\mathrm{p} 53$ following DNA damage by these and other agents is p21, and there is overwhelming evidence to support the seminal role of this transcriptional target in G1 checkpoint response (Deng et al, 1995).

In essence, the DNA damage checkpoint is an integrated network of signal transduction pathways that allows cells to transfer information from the DNA lesion to the cell-cycle machinery via sensor, transducer and effector signalling proteins (Iliakis et al, 2003). This sequence of events culminates in cyclindependent kinase (Cdk) inhibition, which attenuates cell-cycle progression. Inhibition of the binary Cdk4/cyclin D and Cdk2/ cyclin E complexes is associated with activation of the G1-phase checkpoint to prevent G1/S transition, Cdk2/cyclin A with the S-phase checkpoint to slow progression through the S-phase, and Cdc2/cyclin A and Cdc2/cyclin B with the G2-phase checkpoint to prevent G2/M transition (Samuel et al, 2002; Iliakis et al, 2003). Although these various Cdks can be inhibited by the Cip/Kip family members of inhibitors (p21, p27 and p57), p21 is the most critical for inhibiting G1-phase Cdk, primarily since p21 deletion alone can prevent G1-phase arrest (Pietenpol and Stewart, 2002; Samuel et al, 2002), whereas other mechanisms exist to inhibit S- and G2-phase Cdks (Pietenpol and Stewart, 2002).

Our recent studies have demonstrated that DNA damage by cisplatin and the platinum-based analogue diaminocyclohexanediacetatao-dichloro-Pt(IV) (DAP) robustly inhibit G1-phase Cdk complexes in a p53/p21-dependent manner (He et al, 2005, 2011). However, the nature of the inhibited Cdk complex induced by these Pt drugs and other antitumour agents remains uncertain. For instance, it is unclear whether recruitment of a single molecule of p21 is sufficient to inhibit Cdk (Hengst et al, 1998; Adkins and Lumb, 2000) or if it is only a prerequisite for the assembly and catalytic activity of the Cdk complex, with multiple molecules needed to inhibit Cdk activity (Zhang et al, 1994; Harper et al, 1995; LaBaer et al, 1997; Sherr and Roberts, 1999; Coqueret, 2003). More importantly, there is also uncertainty whether other proteins are also recruited to modulate inhibition of the Cdk complex, although the possibility is strong since several proteins, such as c-Myc, PCNA, E2F4 and SET, have been reported to associate with the Cdk complex under basal conditions (Hermeking et al, 1995; Estanyol et al, 1999; Koundrioukoff et al, 2000; Chytil et al, 2004). Therefore, to better define inhibition of G1-phase Cdk complexes by platinum drugs, we have undertaken a proteomic analysis of the inhibited kinase complex. Our studies demonstrate that the size of the inhibited Cdk complex increases substantially, and this is ascribed to PCNA, which co-recruits with p21 and enhances the stability of the Cdk inhibitor within the Cdk complex.

\section{MATERIALS AND METHODS}

Chemicals. DAP was synthesised and characterised as described previously (Khokhar et al, 1997). Cisplatin, MTT and cycloheximide were purchased from Sigma (St Louis, MO, USA), and FBS obtained from BioWhittaker Inc. (Walkersville, MD, USA). LipofectAMINE 2000 (LF2000; cat. no. 11668-019) was purchased from Invitrogen (Carlsbad, CA, USA).

Cell culture and drug treatment. Breast MCF-7 (in MEM), colon HCT-116 (McCoy's 5a), fibrosarcoma HT1080 (DMEM), ovarian A2780 (RPMI-1640) and ovarian OVCA-429 (MEM) tumour cells, all harbouring wild-type p53, were grown as sub-confluent monolayer cultures in medium supplemented with 10\% FBS.
For platinum treatment, cells $\left(1-1.3 \times 10^{6}\right)$ were plated in $100-\mathrm{mm}$ culture dishes and grown for at least $24 \mathrm{~h}$ when the cultures were replaced with fresh medium containing the drug. The cells were then further grown for up to $36 \mathrm{~h}$ and collected either for analysis of cell-cycle distribution by FACS or to prepare cell lysates, as previously described (Kuang et al, 2001).

Immunoblotting, immunoprecipitation and Cdk studies. Immunoblotting, immunoprecipitation and assays for Cdk activity were performed as previously described (Kuang et al, 2001). The antibodies used to immunoprecipitate Cdk4 (sc-601), Cdk2 (sc-163AC), cyclin D1 (sc-718), cyclin E (sc-248), Myc (sc-40), p21 (sc-397AC), and p27 (sc-528) and immunoblot cyclin D1 (sc-718), cyclin E (sc-247), PCNA (sc-56), Myc (sc-40) and p21 (sc-6246) were purchased from Santa Cruz Biotechnology (Santa Cruz, CA, USA). Other primary antibodies used to immunoblot Cdk4 (MS-299), Cdk2 (MS-617) and p27 (MS-256) were obtained from Neomarkers Inc. (Fremont, CA, USA). The primary antibody used to immunoblot $\beta$-actin (A5060) was purchased from Sigma. The horseradish peroxidase-conjugated secondary antibodies were purchased from Amersham Pharmacia (Piscataway, NJ, USA). The immunoblots were developed with ECL detection reagents (Amersham Pharmacia) with different lengths of exposures, and the protein bands on the developed films were quantified with the NIH Image software (version 1.62; Research Services Branch, NIH, Bethesda, MD, USA). The exposures that gave densitometry readings within a linear range were selected. Histone $\mathrm{H} 1$ (for Cdk2/ cyclin E) or retinoblastoma (Rb) (for Cdk4/cyclin D1) was used as the substrate for assessing Cdk activity.

Gel filtration chromatography. The procedure used in these studies has been previously reported by us (He et al, 2006). Briefly, chromatography was conducted at $4{ }^{\circ} \mathrm{C}$ on a $40-\mathrm{ml}$ Ultrogel AcA34 (LKB, Houston, TX, USA) column in an EB buffer, which consisted of $80 \mathrm{~mm} \beta$-glycerophosphate, $20 \mathrm{~mm}$ EGTA, $200 \mathrm{~mm}$ $\mathrm{NaCl}, 15 \mathrm{~mm} \mathrm{MgCl}_{2}$ and $1 \mathrm{~mm}$ dithiothreitol. In each gel filtration study, $0.5 \mathrm{ml}$ of protein standards or crude cell lysates supplemented with $0.5 \mathrm{mg}$ of purified GST (internal standard) was loaded onto the column, chromatographed and 1-ml fractions collected. A $40-\mu \mathrm{l}$ aliquot of fractions were separated by $12.5 \%$ sodium dodecyl sulfate polyacrylamide gel electrophoresis (SDS-PAGE), the gel-separated proteins transferred onto nitrocellulose membranes and stained with $0.1 \%$ Ponceau $S$ in $5 \%$ acetic acid to reveal the elution profiles of GST and other cellular proteins. The membranes were then immunoblotted with anti-cyclin D1 or anti-cyclin $\mathrm{E}$ antibody. The cyclin D1 or E band was quantified by densitometry, and the band intensities normalised to the strongest signal, which was arbitrarily defined as 100 .

Sucrose gradient analysis. Crude cell lysates from control or platinum drug-treated cells were layered on top of a $10-30 \%$ sucrose gradient and centrifuged for $16 \mathrm{~h}$ at 60000 r.p.m. at $4{ }^{\circ} \mathrm{C}$ using an SW50.1 rotor in a Beckman L70 centrifuge (Fullerton, CA, USA). Twenty fractions of $180 \mu \mathrm{l}$ were collected from the top of the tube, proteins in collected fractions concentrated by TCA precipitation, and samples analysed by SDS-PAGE and immunoblotting.

Immunoprecipitation for proteomic analysis. Our previously reported procedure was followed (He et al, 2006). Essentially, 15 -ml crude cell lysates ( $\sim 10 \mathrm{mg}$ protein per $\mathrm{ml}$ ) from control or platinum drug-treated cells were first pre-absorbed for $4 \mathrm{~h}$ at $4{ }^{\circ} \mathrm{C}$ with $200 \mu \mathrm{l}$ of protein-A agarose (Sigma). To isolate the Cdk4/ cyclin D complex, the cell lysates were then pre-cleared and incubated overnight at $4{ }^{\circ} \mathrm{C}$ with $25 \mu \mathrm{g}$ of polyclonal anti-cyclin D1 antibodies, or rabbit IgG (Sigma) as a control, that were conjugated covalently to $30 \mu \mathrm{l}$ of Affi-prep protein A beads (Bio-Rad, Hercules, CA, USA) by the dimethylpimelimidate-catalysed reaction (Schneider et al, 1982). The Cdk2/cyclin E complex was similarly 
isolated using $25 \mu \mathrm{g}$ of monoclonal anti-cyclin E antibody, using mouse IgG (Sigma) as a control, that were covalently linked to $30 \mu \mathrm{l}$ of protein-G sepharose (Amersham). After incubation, the beads were washed six times with buffer containing $0.5 \%$ $\mathrm{NP}-40,150 \mathrm{~mm} \mathrm{NaCl}, 2 \mathrm{~mm}$ EDTA, 2 mм EGTA, $5 \mathrm{~mm}$ sodium $\beta$-glycerophosphate, $10 \mathrm{~mm} \mathrm{NaF}, 10 \%$ glycerol, $1 \mathrm{~mm} \mathrm{DTT}$, and $1 \mathrm{~mm}$ PMSF in $50 \mathrm{~mm}$ Tris- $\mathrm{HCl}$ (pH7.4) supplemented with the protease inhibitor cocktail (Roche, Indianapolis, IN, USA), and the precipitated proteins eluted with SDS-PAGE sample buffer and separated using a $12.5 \%$ SDS gel. Each gel slab was then fixed overnight in $40 \%$ ethanol $/ 10 \%$ acetic acid and washed sequentially with $40 \%$ ethanol for $10 \mathrm{~min}$ and then deionised water for $15 \mathrm{~min}$. The gel was next treated for $1 \mathrm{~min}$ with $0.02 \%$ sodium thiosulfate, rinsed twice for $1 \mathrm{~min}$ each with distilled water, submerged in $0.1 \%$ silver nitrate for $30 \mathrm{~min}$, and then developed in $0.04 \%$ formalin in $3 \%$ sodium carbonate until a desired staining intensity was achieved. The reaction was stopped by the addition of $1 / 10$ volume of $2.3 \mathrm{M}$ citric acid to the developer and incubation of the gel in this solution for $15 \mathrm{~min}$. The gel was then rinsed three times with distilled water and stored in distilled water at $4{ }^{\circ} \mathrm{C}$ (Shevchenko et al, 1996).

Polypeptide identification by mass spectrometry. Bands of interest on silver-stained gels were excised, de-stained with the Invitrogen Silver Quest kit, and washed five times with distilled water and then twice with $25 \mathrm{~mm}$ ammonium bicarbonate in $50 \%$ acetonitrile, as previously reported ( $\mathrm{He}$ et al, 2006). The bands were next digested $(20 \mathrm{~h})$ with trypsin (Promega, Madison, WI, USA) in $25 \mathrm{~mm}$ ammonium bicarbonate, and the resulting peptide fragments extracted twice with $0.01 \%$ trifluoroacetic acid $/ 50 \%$ acetonitrile and concentrated to $<10 \mu \mathrm{l}$ by Speedvac (Thermo Savant, Holbrook, NY, USA). After purification by HPLC using C-18 Ziptips (Millipore, Bedford, MA, USA) and 2\% acetonitrile/ $0.1 \%$ formic acid to wash and $70 \%$ acetonitrile/ $0.1 \%$ formic acid to elute the peptides, the acetonitrile was removed from the eluates by centrifugation in a Speedvac. Peptide mass fingerprinting (PMF) analysis was performed on a Voyager DE-STR linear MALDI TOF (Applied Biosystems, Framingham, MA, USA) in a positive ion and a reflected mode (Vestal and Juhasz, 1998), as described by us (Koomen et al, 2005). Dried droplet deposits of $\alpha$-cyano-4hydroxycinnamic acid were prepared by mixing the peptide solutions $1: 1$ with $10 \mathrm{mg} \mathrm{ml}^{-1}$ matrix in methanol. Database search utilised the Mascot (http://www.matrixscience.com) and Protein Prospector (http://prospector.ucsf.edu) websites. The PMF results were validated by peptide sequencing on an LCQ DecaXP electrospray quadrupole ion trap mass spectrometer (Thermo Finnigan, San Jose, CA, USA) coupled to an HP 1090 liquid chromatography system (Agilent, Palo Alto, CA, USA) (Davis and Lee, 1998) and a $0.3-\mathrm{mm}$ C-18 column (Vydac, Hesperia, CA, USA). The solvent system was composed of solution A (2\% acetonitrile/0.01\% trifluoroacetic acid) and solution B (98\% acetonitrile/ $0.01 \%$ trifluoroacetic acid) that were applied as a 40 -min linear gradient from $5 \%$ to $60 \%$ of B to elute the peptides. Data-dependent acquisition was conducted for $60 \mathrm{~min}$ by using two MS-MS steps after each MS1. Database search with the MS-MS data was performed with Sonar (Genomic Solutions, Ann Arbor, MI, USA).

Plasmids and transfection. Wild-type myc-p21 vector was prepared as described previously by us (He et al, 2006). Briefly, p21 cDNA was amplified by PCR, digested with both EcoRI and XhoI enzymes and subcloned into pCMV-Myc vector (Clontech, Mountain View, CA, USA). Two mutant-p21 vectors p21 $1^{\text {T145E }}$ (p21TE) and $\mathrm{p} 21^{\mathrm{T} 145 \mathrm{E} / \mathrm{S} 146 \mathrm{D}}(\mathrm{p} 21 \mathrm{ED})$ were prepared using the QuickChange II XL site-directed mutagenesis kit, following the manufacturer's instruction (Agilent, Santa Clara, CA, USA), to mimic phosphorylation at these sites that inhibits $\mathrm{p} 21$ binding to PCNA (Scott et al, 2000; Rossig et al, 2001). The primers used were as follows: p21TE: 5'-GGTCGAAAACGGCGGCAGGAGAG CATGACAGATTTCTAC- $3^{\prime}$ and $5^{\prime}$-GTAGAAATCTGTCATGC TCTCCTGCCGCCGTTTTCGACC-3'; p21ED: 5'-GGTCGAAAA CGGCGGCAGGAGGACATGACAGATTTCTACCAC-3 $3^{\prime}$ and $5^{\prime}-\mathrm{G}$ TGGTAGAAATCTGTCATGTCCTCCTGCCGCCGTTTTCGACC- ${ }^{\prime}$. The wild-type pCMV-myc-PCNA vector was prepared in a similar manner, using the PCR primers $5^{\prime}$-CCGGAATTCGGATCCC GATGTTCGAGGCGCGCCTG- $3^{\prime}$ and $5^{\prime}$-CCGCTCGAGCTAA GATCCTTCTTCATCCTCG-3' for amplification. The mutant form of myc-PCNA vector (Y114A) was prepared by site-directed mutagenesis using the primers 5'-CCAAACCAGGAGAAAGTTT CAGACGCTGAAATGAAGTTGATGGATTTAGA- $3^{\prime}$ and $5^{\prime}$-T CTAAATCCATCAACTTCATTTCAGCGTCTGAAACTTTCTCC TGGTTTGG-3'.

Empty, wild-type or mutant myc-p21 or myc-PCNA vector was transfected into tumour cells using LF2000, following the manufacturer's instructions. Briefly, cells were exposed to the transfection mixture containing LF2000 and plasmids for $5 \mathrm{~h}$, washed and then replenished with normal media. Half-life of transfected p21 was determined by densitometric readings of bands in immunoblots of lysates from cells collected serially following exposure to $3 \mu \mathrm{M}$ cycloheximide to prevent further p21 synthesis. The half-life was determined from fitting the data to an exponential decay equation using the GraphPad Prism computer program (Graphpad Software, Inc., La Jolla, CA, USA).

In vitro binding of p21 to PCNA. In vitro p21-PCNA binding was assessed as described previously (He et al, 2005). Briefly, tumour cells were cultured in the presence or absence of the platinum drug for $24 \mathrm{~h}$ and crude lysates at $10 \mathrm{mg} \mathrm{ml}^{-1}$ protein were prepared from both control and drug-treated cells. To obtain boiled cell lysate, the drug-treated cell lysate was heated at $100{ }^{\circ} \mathrm{C}$ for $5 \mathrm{~min}$ and the soluble fraction was recovered after centrifugation at $13000 \mathrm{~g}$ for $10 \mathrm{~min}$. Depletion of p21 or p27 from the soluble fraction was achieved by immunoprecipitation with excess anti-p21 or anti-p27 antibodies. From the control cell lysate, Cdk2 complex was immunoprecipitated with anti-Cdk2 antibodies $(1 \mu \mathrm{g}$ antibodies per $100 \mu$ l cell lysate) immobilised onto agarose beads. After three washes, the beads were incubated with $5 \mu \mathrm{l}$ of untreated cell lysate (to provide endogeneous PCNA), $40 \mu \mathrm{l}$ of boiled drugtreated cell lysate (original, p21 or p27 pre-depleted) in a final volume of $50 \mu \mathrm{l}$ supplemented with the cell extraction buffer at room temperature for $30 \mathrm{~min}$. After the beads were washed, they were separated by SDS-PAGE and immunoblotted for PCNA, p21 and p27 as described above.

\section{RESULTS}

DAP-induced cell-cycle arrest. We have previously reported that DAP activates G1 checkpoint response (Kuang et al, 2001). To identify an optimal drug concentration for proteomic analysis of inhibited G1-phase Cdk and G1 arrest, A2780 tumour cells were exposed to a range of DAP concentrations for $36 \mathrm{~h}$ and cell-cycle distribution examined. Figure 1A demonstrates changes in cellular DNA histograms with increasing DAP concentrations, whereas Figure 1B summarises the distribution of cells in G1, S and G2/M phases as determined from these histograms. The figures reveal that cell numbers in G1 increase with increasing DAP concentration up to $0.8 \mu \mathrm{M}$, and this is accompanied with a concomitant decrease in $\mathrm{S}$ and G2/M cells. Above this concentration, G1 cells decrease progressively, whereas cells in $S$ and $\mathrm{G} 2 / \mathrm{M}$ begin to increase. These results demonstrate selective activation of G1 checkpoint at low DAP concentrations $(<0.8 \mu \mathrm{M})$, but combined G1, S and G2/M checkpoint activations at higher concentrations $(>0.8 \mu \mathrm{M})$. On the basis of these studies, $0.6 \mu \mathrm{M}$ DAP was chosen for our proteomic investigations since this concentration ensured 
A
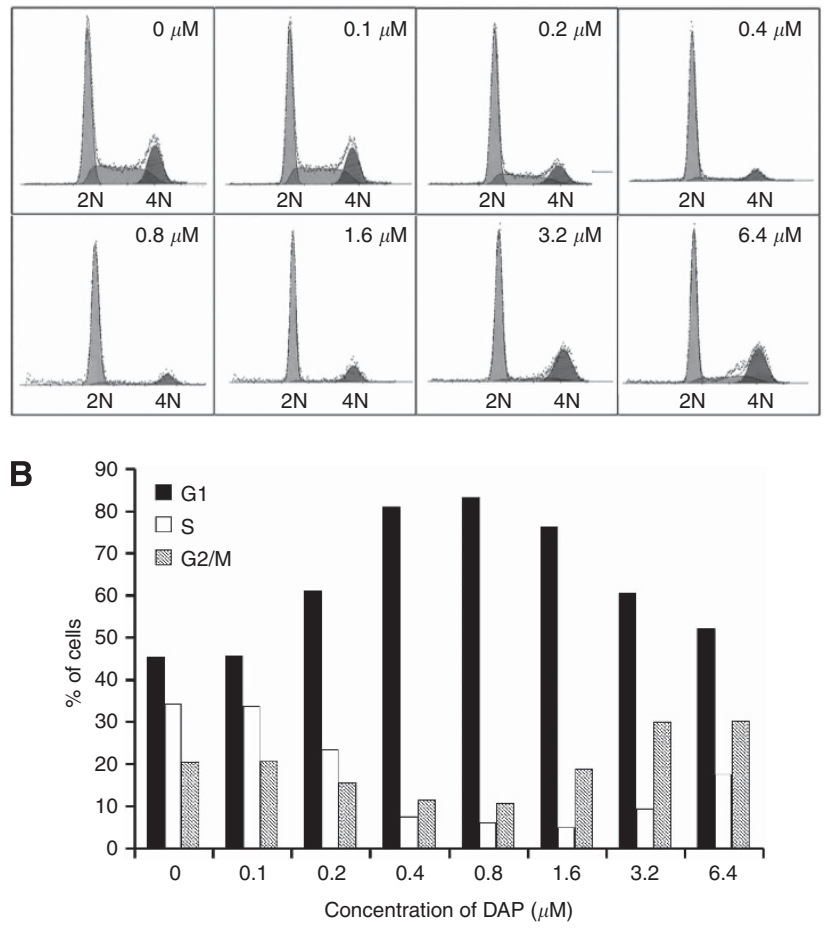

Figure 1. The effect of DAP on cell-cycle kinetics. A2780 cells were incubated with DAP $(0-6.4 \mu \mathrm{M})$ for $36 \mathrm{~h}$ and then analysed for cell-cycle distribution by FACS. DNA content histograms (A) and quantified percentages of cells distributed in different phases of the cell cycle (B) are shown.

the absence of possible interference from any effects due to $S$ and $\mathrm{G} 2 / \mathrm{M}$ arrests, and also this concentration did not induce cell death during the 36-h time course of the study (data not shown). The lack of G2/M arrest is consistent with this concentration of DAP as having no effect on the kinase activity of Cdc2/cyclin A in G2 phase of the cell cycle (Kuang et al, 2001).

Increase in size of the inhibited Cdk4 and Cdk2 complexes. To grossly assess whether inhibited G1-phase Cdk complexes bind proteins other than $\mathrm{p} 21$, an increase in the size of the inhibited complex following treatment of A2780 cells with $0.6 \mu \mathrm{M}$ was examined by gel filtration and gradient sedimentation analysis. The results from this investigation are shown in Figure 2.

When crude lysates from control or DAP-treated A2780 cells were fractionated on Ultrogel AcA34 gel column, and the fractions examined by immunoblots for cyclin D1 (as a marker for the Cdk4 complex) and cyclin E (for the Cdk2 complex), it was apparent that Cdk complexes from DAP-treated cells eluted earlier, suggesting an increase in the molecular size (Figure 2A and C). To assess kinase activities, Cdk was immunoprecipitated from fraction 26 of control and fraction 24 of DAP-treated cell lysate that represented peak levels of cyclin D1 (Figure 2A) or cyclin E (Figure 2C) and examined for $\mathrm{Cdk} 4$ or $\mathrm{Cdk} 2$ activities, respectively. Robust activities of both kinases were observed in control fraction 26, which equates to $\sim 140 \mathrm{kDa}$ for the size of the complex, but the activities were reduced by over $95 \%$ in fraction $24(\sim 290 \mathrm{kDa})$ arising from DAP-treated cells (Figure $2 \mathrm{~B}$ and D). This demonstrates that inhibition of kinase activities following DAP treatment is associated with an increase in the size of the Cdk complex by $\sim 150 \mathrm{kDa}$. The increase in size was confirmed by sucrose gradient, which demonstrated a shift of the Cdk4 (Figure 2E) and Cdk2 complex (Figure 2F) in DAP-treated samples to a higher sucrose concentration.
Proteomic analysis identifies PCNA in inhibited G1-phase Cdk complexes. On the basis of the data in Figure 2, it was reasonable to consider that the $150-\mathrm{kDa}$ increase in size of the inhibited Cdk complex is likely due to recruitment of proteins other than p21 $(21 \mathrm{kDa})$. Therefore, we performed large-scale cyclin D1 and E immunoprecipitates from DAP-treated A2780 tumour cells for proteomic analysis. The immunoprecipitates were resolved by SDS-PAGE and silver stained. Resolution of proteins in cyclin D1 and cyclin E immunoprecipitates from control (lane c) and DAPtreated cells (lane d) are shown in Figure 3A and B, respectively, together with IgG (lane a) and respective cyclin antibody controls (lane b). Six polypeptides of interest were visualised in cyclin D1 immunoprecipitates from DAP-treated cells. By mass spectrometry and database searches, they were identified as PCNA, cyclin D1, cyclin D2, Cdk4, Cdk2 and p21. The prominence of Cdk4, cyclin D1 and p21 is consistent with our reported observation that DAP upregulates p21 and increases the level of the Cdk4/cyclin D1 complex (He et al, 2006). The presence of cyclin D2 and Cdk2 is not unexpected due to the reported cross-reactivity of D1 antibodies with D2 (Lukas et al, 1995) and association of cyclin D1 with Cdk2 (Xiong et al, 1992; Malumbres et al, 2004). Proliferating cell nuclear antigen was only detected after DAP treatment. Similar results were seen with cyclin E immunoprecipitates (Figure 3B), where three polypeptide bands of interest in DAP-treated cell lysates were identified as cyclin E, PCNA and Cdk2. As with Cdk4/cyclin D1, the level of Cdk2/cyclin E complex is increased by DAP (He et al, 2006), and this explains the prominence of $\mathrm{Cdk} 2$ and cyclin E bands in the blot. On the other hand, the p21 band in this blot was difficult to identify because of its poor resolution from a strongly staining non-specific overlapping band. Thus, DAP treatment induces recruitment of PCNA into the Cdk4/cyclin D and Cdk2/cyclin E complexes, and this was confirmed by gel co-elution of PCNA with Cdk4 or Cdk2 in immunoblots (Figure 3C).

Recruitment of PCNA into the Cdk4 and Cdk2 complex following DAP treatment of A2780 cells was validated by PCNA immunoblots of Cdk immunoprecipitates (Figure 4A). Proliferating cell nuclear antigen was detected in the Cdk 4 complex by $6 \mathrm{~h}$ after DAP treatment, but became prominent at $18 \mathrm{~h}$ and remained so until the experiment was terminated at $36 \mathrm{~h}$. Proliferating cell nuclear antigen was also prominently represented in the C dk2 complex in the $18-36 \mathrm{~h}$ time range. It is noteworthy that although PCNA is abundantly present in A2780 cells, it is relatively undetectable in control active Cdk4 or Cdk2 complex (Figure 4A). To exclude the possibility that PCNA recruitment into the Cdk complex following DAP treatment was specific to only A2780 cells, four additional tumour models (HCT-116, HT1080, MCF-7 and OVCA-429) were also examined for PCNA binding to the Cdk2 complex. These tumour models when exposed to DAP at concentrations inducing selective G1 arrest (He et al, 2005) (see figure legend for details) similarly demonstrated recruitment of p21 (Figure 4B) and PCNA (Figure 4C) into the Cdk complex, and indicated that this PCNA recruitment, like p21, is a general response to DAP treatment and is present in the complex at the time when Cdk activity is inhibited (Figure 4D). Similar results were also observed with cisplatin in the representative A2780 model using a concentration of $1 \mu \mathrm{M}$ that was equitoxic with DAP (data not shown), and this indicates that the recruitment of PCNA is not platinum drug specific.

Recruitment of PCNA into the Cdk complex is p21 dependent and occurs as a trimer. Results in Figures 3 and 4 demonstrate that PCNA is present in abundance in cells, but only becomes bound to the G1-phase Cdk complex in parallel with p21 binding and correlates with inhibition of Cdk/cyclin activity. Since PCNA binds to not only p21, but also Cdk and cyclin (Maga and Hubscher, 2003), the basis for recruitment of PCNA into the 

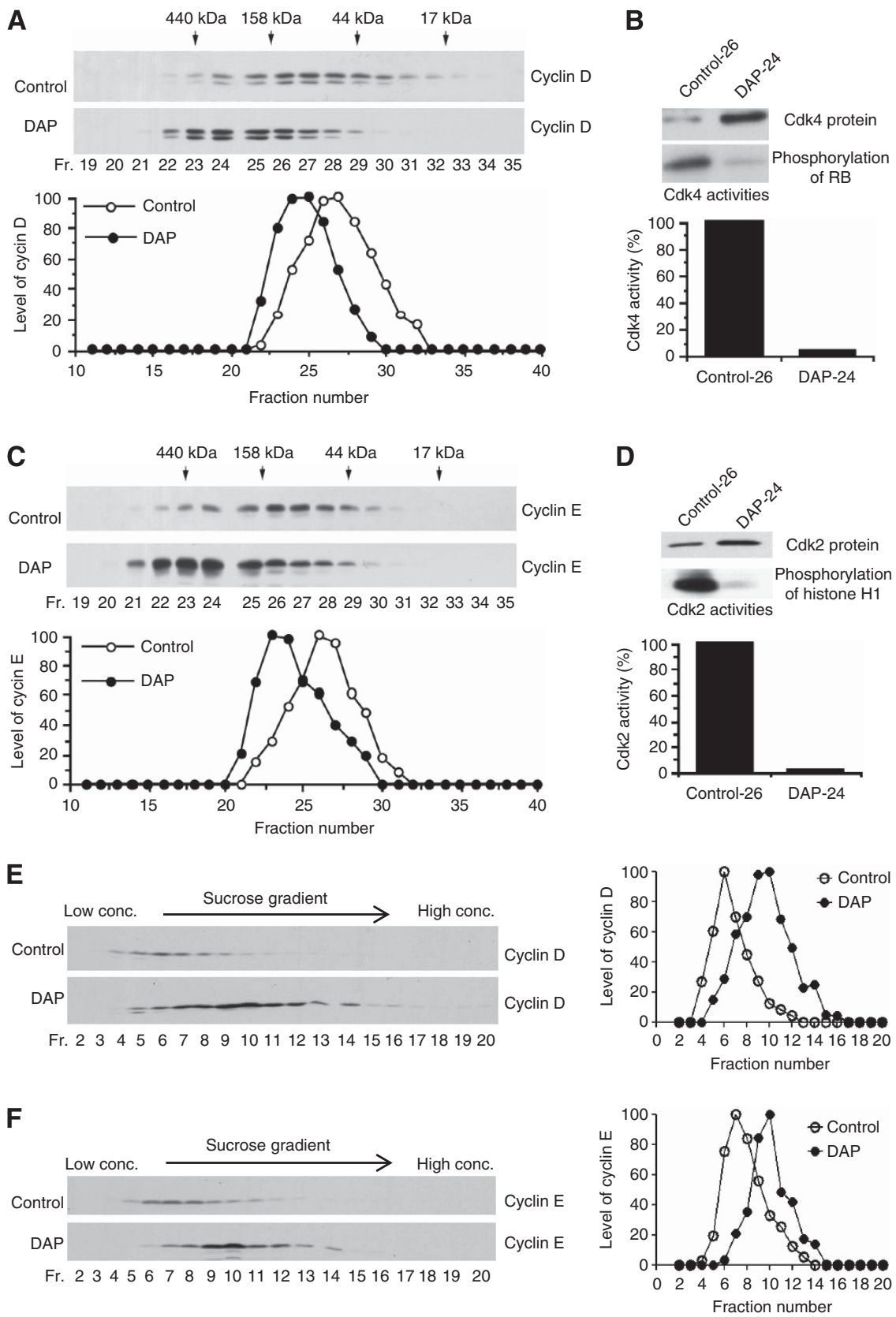

Figure 2. Increase in the molecular size of the inhibited Cdk4 and Cdk2 complexes in DAP-treated cells. Crude cell lysates prepared from control or 24-h DAP-treated A2780 cells were fractionated according to size by gel filtration, proteins in fractions (Fr) visualised by immunoblotting, the bands of interest quantified by densitometry and normalised (A-D). The size fractionation profile of cyclin D and molecular markers was established (A) and fractions with peak cyclin D levels (fraction 26 of control and fraction 24 after DAP treatment) selected to prepare Cdk4 immunoprecipitates for estimation of kinase activity using $\mathrm{Rb}$ as the substrate for ${ }^{32} \mathrm{P}$-phosphorylation (B). Similar approaches were taken for cyclin E distribution (C) and estimation of Cdk2 kinase activity against histone $\mathrm{H} 1$ as the substrate (D). Crude cell lysates were also subjected to 10-30\% sucrose gradient sedimentation for size distribution of cyclin $D(E)$ and cyclin $E(F)$ complex.

$\mathrm{Cdk} /$ cyclin complex is uncertain. However, levels of PCNA in immunoprecipitates of Cdk4 or Cdk2 from control A2780 tumour cells were either low or undetectable (Figure 4A), and this implicates p21 as being responsible for recruitment of PCNA into the inhibited G1-phase Cdk/cyclin complex, either via a direct physical interaction with p21 or a change in Cdk or cyclin conformation as a result of binding of p21 to $\mathrm{Cdk} /$ cyclin. To provide definitive evidence for the underlying basis for PCNA recruitment, and the consequence of this on Cdk/cyclin activities, a series of investigations were undertaken in control and DAP-treated A2780 tumour cells.
The study to investigate a direct or indirect effect of p21 on PCNA recruitment into the Cdk complex involved reconstitution of excess Cdk2 immunoprecipitated (using antibodies bound to agarose beads) from control cells with control cell lysates (as a source of PCNA) and either boiled cell lysate from DAP-treated cells that removed PCNA (but not p21 and p27) or this boiled lysate from which p21 or p27 was first immunodepleted. After 30-min incubation at room temperature, the agarose beads were washed and the bound proteins resolved by SDS-PAGE and immunoblotted. The results in Figure 5A demonstrate that PCNA was minimally bound to Cdk2 in control incubations 
A

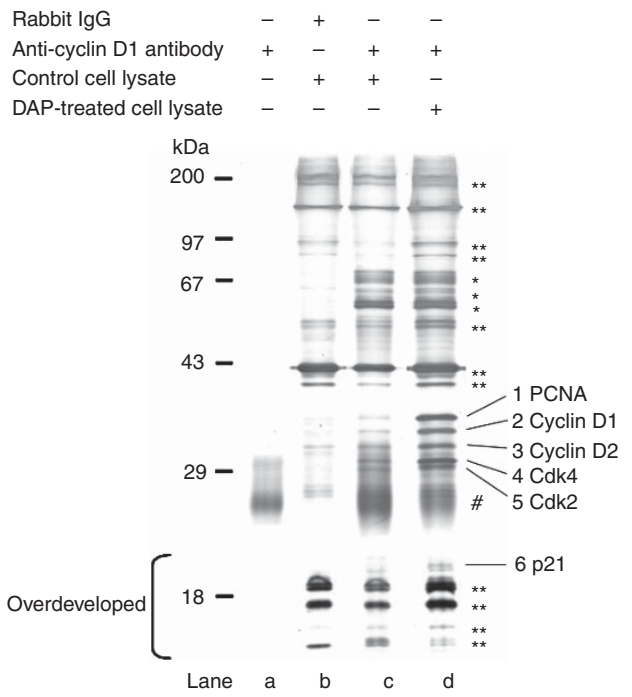

B

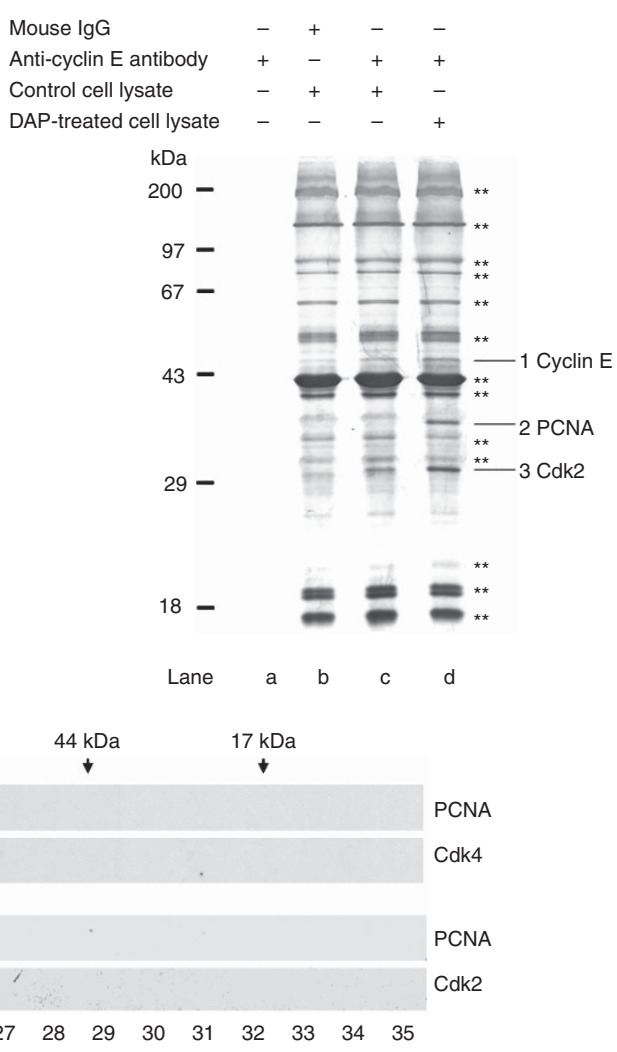

Figure 3. DAP treatment induces recruitment of PCNA into Cdk4 and Cdk2 complexes. Covalently linked anti-cyclin D or control rabbit lgG was used for large-scale preparation of immunoprecipitates from untreated or DAP-treated A2780 cell lysates, and the eluted proteins from antibody beads were resolved by SDS-PAGE and visualised by silver staining (A). Protein bands seen to increase in intensity following DAP treatment were analysed by mass spectrometry, and their identity is indicated. Cyclin E immunoprecipitates were prepared and analysed in an identical manner (B). Lane a, control anti-cyclin D or E antibody beads; Lane b, rabbit (A) or mouse (B) IgG immunoprecipitates from control cell lysate; Lane C, anti-cyclin D or E immunoprecipitates from control cell lysate; Lane d, anti-cyclin D or E immunoprecipitates from DAP-treated cell lysate. The single asterisk $\left(^{*}\right)$ indicates cross-reactive polypeptides that were immunoprecipitated by the anti-cyclin D or anti-cyclin E antibodies, and the double asterisk $\left.{ }^{(* *}\right)$ is associated with non-specific polypeptides that bound to rabbit or mouse lgG. The \# symbol indicates light chain and cleaved heavy chain of the precipitating antibody. The crude cell lysates from control or 24-h DAP-treated cells were also fractionated by gel filtration, exactly as indicated in Figure 2, and the fractions immunoprecipitated (IP) with cyclin D or E antibodies and immunoblotted for Cdk4, Cdk2 and PCNA (C).

(lanes 1 and 2) or in the presence of p27 alone (lane 4), but the binding increased substantially only in the presence of p21 (lanes 3 and 5). Thus, the binding of PCNA was likely due to a direct protein-protein interaction with p21, and not a consequence of Cdk inhibition since the Cdk inhibitor p27 that lacks the PCNA-binding domain had no effect. To corroborate this, phosphomimetic mutants p21TE and p21ED were created by respectively mutagenising the T145 and T145/S146 sites of myctagged wild-type p21 (p21wt) and transfected into A2780 tumour cells. Failure of these mutants to bind to PCNA has been previously reported (Scott et al, 2000; Rossig et al, 2001), and this was confirmed in myc and PCNA immunoblots of myc immunoprecipitates (Figure 5B, lanes 5 and 6 vs lane 4). Similarly, Cdk2 immunoprecipitation followed by immunoblot analysis demonstrated that both wild-type and mutant $\mathrm{p} 21$ bound to Cdk2, but cobinding of PCNA to the Cdk complex occurred only in the presence of p21wt (Figure 5C). However, p21 mutants, like wildtype $\mathrm{p} 21$, inhibit $\mathrm{Cdk}$, as is evident by diminished in vitro $\mathrm{Cdk}$ activity against the substrate histone $\mathrm{H} 1$ (Figure $5 \mathrm{C}$ ) or by an endogeneous cellular decrease in hyperphosphorylated form (upper band) and a concomitant increase in hypophosphorylated form (lower band) of the $\mathrm{Rb}$ substrate (Figure 5D). This consolidates the conclusion that PCNA is not recruited as a result of Cdk inhibition.
These results indicate that PCNA and p21 interact directly and are co-recruited into the Cdk complex, and that the presence of PCNA is not required for p21-dependent inhibition of Cdk. From a proteomic consideration, however, recruitment of a single molecule each of PCNA and p21 to form a tetrameric complex still does not fully explain the $\sim 150-\mathrm{kDa}$ difference between the molecular size of the active and inhibited Cdk complex. Since PCNA functions as a DNA processivity factor in a homotrimeric form (Maga and Hubscher, 2003), it was possible that PCNA may also be bound to p21 in the Cdk complex as a homotrimer. This possibility was investigated by studies involving co-transfection of myc-p21wt with either myc-tagged wild-type PCNA (wt-PCNA) or a mutant myc$\mathrm{PCNA}^{\mathrm{Y} 114 \mathrm{~A}}$ that cannot form the homotrimer (Jonsson et al, 1995). Co-transfections in A2780 cells resulted in good expression of p21 and PCNA, as seen in immunoblots of cell lysates (Figure 6A, upper panel). When these lysates were immunoprecipitated with Cdk4 (middle panel) or Cdk2 antibodies (lower panel), PCNA was co-immunoprecipitated only when wt-PCNA was expressed and in conjunction with co-expression of p21wt. Essentially similar results were obtained when cells transfected with either wt-PCNA or $\mathrm{PCNA}^{\mathrm{Y} 114 \mathrm{~A}}$ were exposed to DAP to increase endogeneous expression of $\mathrm{p} 21$ as a result of DNA damage response (Figure 6B). These results indicate that PCNA is co-recruited with p21 into the Cdk complex primarily as a homotrimer. 
A

Duration of DAP treatment $(\mathrm{h})$
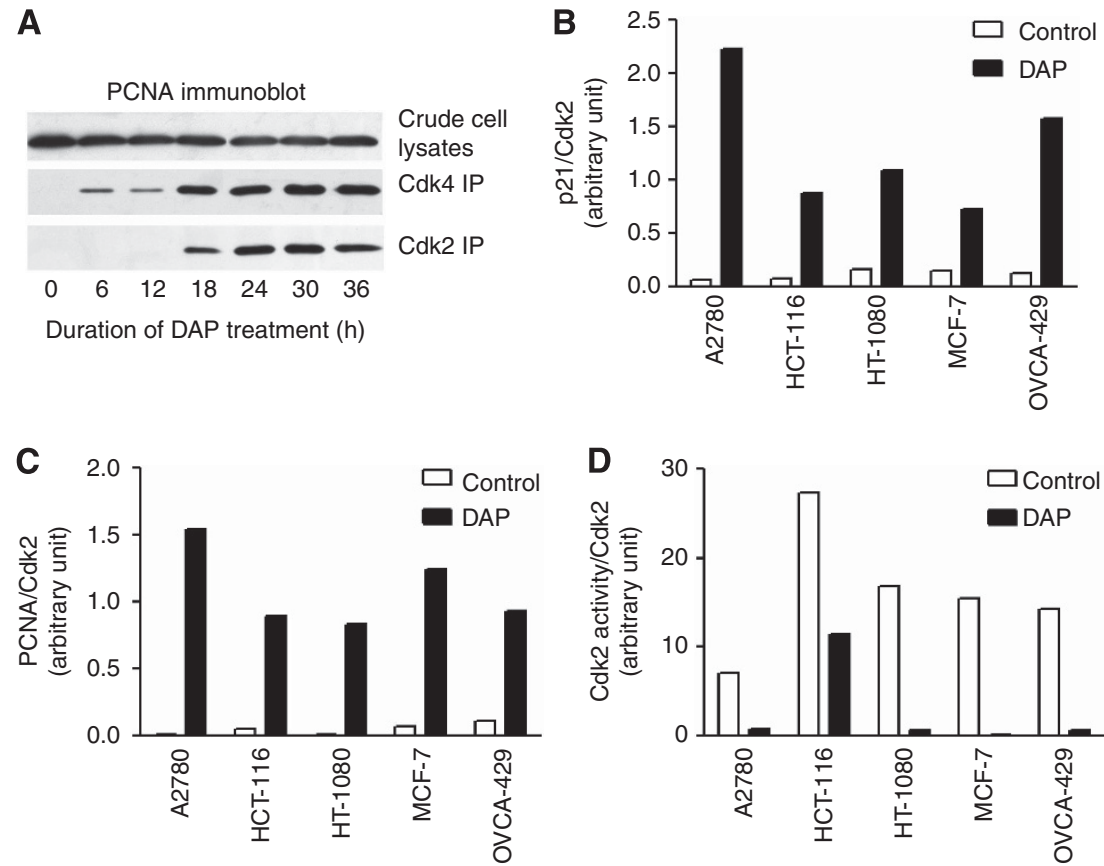

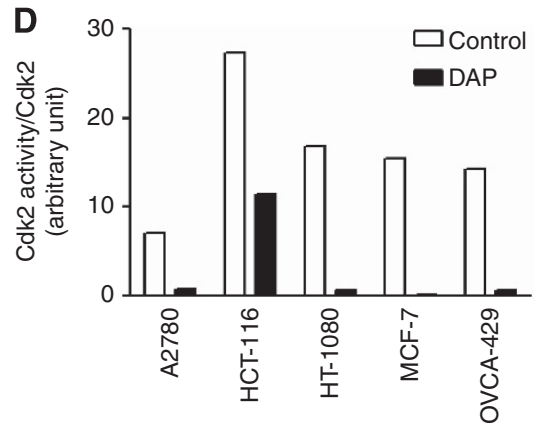

Figure 4. Recruitment of PCNA into Cdk4 and Cdk2 complexes correlates with DAP-induced inhibition of Cdk4 and Cdk2 activities. Crude cell lysates of A2780 cells treated with DAP for the indicated length of time were immunoprecipitated with either anti-Cdk4 or anti-Cdk2 antibody, and the lysates and immunoprecipitates (IP) immunoblotted for PCNA (A). Additional cell lines exposed to DAP (MCF-7, 0.4 $\mu \mathrm{M}$; HCT-116, $2 \mu \mathrm{M}$; OVCA-429, $2 \mu \mathrm{M} ; \mathrm{HT} 1080,4 \mu \mathrm{M}$ ) for $24 \mathrm{~h}$ were similarly processed to isolate Cdk2 immunoprecipitates, which were then either separated by SDS-PAGE and immunoblotted for p21 and PCNA or assessed for kinase activity by ${ }^{32} \mathrm{P}$-phosphorylation of histone $\mathrm{H} 1$. The band signals from p21 (B), PCNA (C) and ${ }^{32} \mathrm{P}$-cpm (counts per minute) (D) are shown normalised for band intensity associated with Cdk2 from the immunoblot.
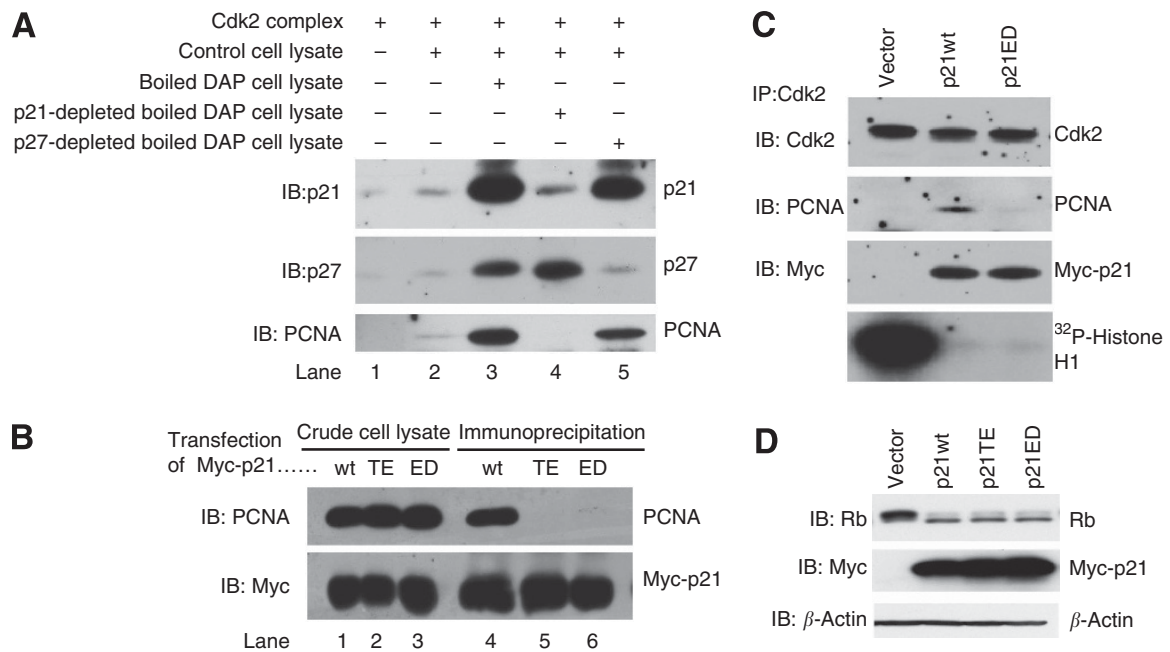

Figure 5. The recruitment of PCNA by Cdk complex is p21 dependent. Cdk2 immunoprecipitate (using antibodies bound to agarose beads) from control A2780 cell lysate, control lysate (as a source for PCNA), and boiled, p21- or p27-immunodepleted lysate from A2780 cells previously exposed to $0.6 \mu \mathrm{M}$ DAP for $24 \mathrm{~h}$ were incubated for $30 \mathrm{~min}$ at room temperature, the beads washed and bound proteins identified by immunoblot (IB) analysis (A). In a separate study, myc immunoprecipitates from lysates of A2780 cells transfected $24 \mathrm{~h}$ earlier with wild type (wt) or mutant (TE or ED) myc-p21 were prepared and the bound proteins then visulaised by SDS-PAGE/immunoblot procedure (B). Alternatively, lysates from A2780 cells, transfected with myc-p21 (wt or ED) $24 \mathrm{~h}$ earlier, were used to immunoprecipitate (IP) Cdk2 complex, which was then either separated by SDSPAGE and immunoblotted with the indicated antibodies or used for estimation of kinase activity using histone $\mathrm{H} 1$ (C). The effect of transfected myc-p21 (wt, TE or ED) on intracellular Cdk activity in A2780 cells was assessed by monitoroing the mobility shift of Rb from a hyper- to a hypophosphorylated state in immunoblots (D).

Endogeneous PCNA stabilises p21 in the Cdk complex. The presence of PCNA as a homotrimer in the quartenary Cdk complex was a seminal observation but did not explain the underlying purpose of PCNA recruitment. However, the results in Figure $6 \mathrm{~B}$ provided a clue that exogeneous expression of wt-PCNA may stabilise endogeneous basal p21 compared with empty vector control (lane 3 vs 1) or mutant $\mathrm{PCNA}^{\mathrm{Y} 114 \mathrm{~A}}$ (lane 3 vs 5). This possibility was examined by measuring the half-life of wild-type and mutant p21 transfected in A2780 cells. The results indicate that the p21TE and p21ED mutants decay about two-fold faster than p21wt $\left(t_{1 / 2}: \sim 0.5\right.$ vs $\left.1.2 \mathrm{~h}\right)$ when examined in crude cell lysates (Figure 7A). Similar results were seen for p21 bound to the 
A

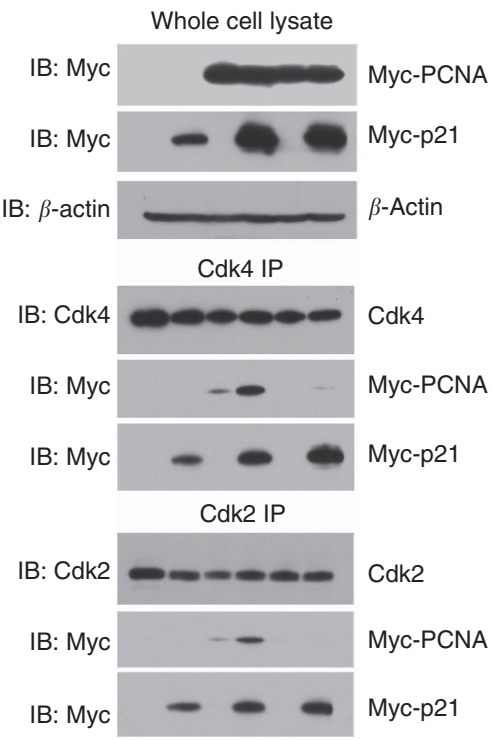

Wt-PCNA $\quad-\quad++--$

Mutant-PCNA - --++

Myc-p21 wt -+-+-+

Vector $+\quad-\quad--$

Lane $\quad 1 \quad 2 \quad 3 \quad 4 \quad 56$
B

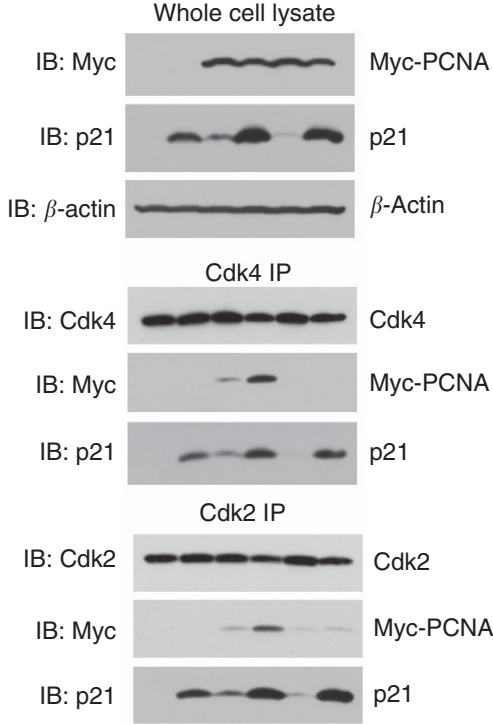

Wt-PCNA $\quad-\quad++-$

Mutant-PCNA ---++

DAP $\quad-+-+-+$

Vector $\quad+----$

Lane $\quad 1 \quad 2 \quad 3 \quad 4 \quad 56$

Figure 6. PCNA binds to Cdk complex as a trimer. A2780 cells were transfected for $5 \mathrm{~h}$ with wild-type (wt) myc-p21, myc-PCNA (wt-PCNA) and/or myc-PCNA engineered to prevent its homotrimerisation (mutant-PCNA), and lysates prepared $19 \mathrm{~h}$ later (A). Alternatively, cells transfected with wt-PCNA or mutant-PCNA for $5 \mathrm{~h}$ were exposed to DAP $7 \mathrm{~h}$ later to upregulate $\mathrm{p} 21$, and lysates prepared after a further $24 \mathrm{~h}$ (B). Cdk4 and Cdk2 immunoprecipitates (IP) from lysates were prepared, resolved by SDS-PAGE and immunoblotted with the indicated antibodies.
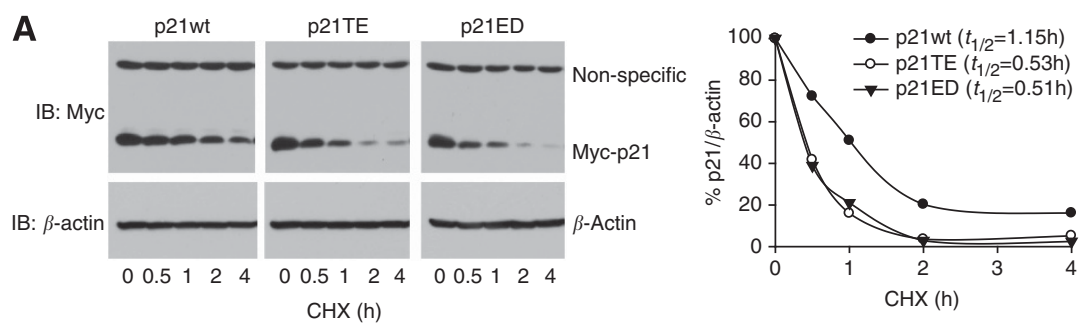

\section{B}
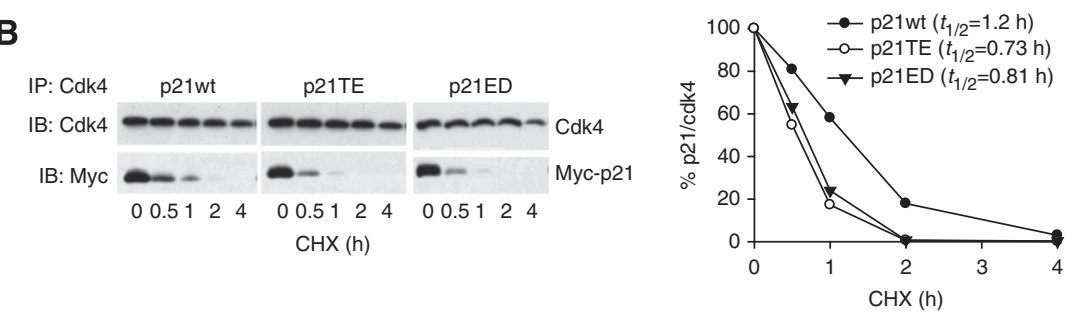

C
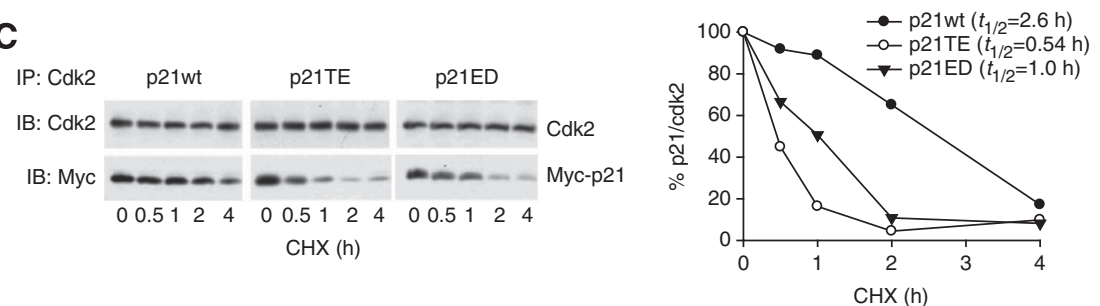

Figure 7. Inhibiting PCNA binding decreases the half-life of p21 in A2780 cells. A2780 cells were transfected with equal amounts of wild-type (p21wt) or mutant (p21TE and p21ED) p21, and $24 \mathrm{~h}$ later the cells were incubated with $3 \mu \mathrm{m}$ of cyclohexmide (CHX) for up to $4 \mathrm{~h}$. Cells were collected at timed intervals after adding CHX (set as time zero), and cell lysates (A) or immunoprecipitates (IP) of Cdk4 (B) and Cdk2 (C) from lysates prepared, resolved by SDS-PAGE and immunoblotted with the indicated antibodies. The myc-p21, Cdk and $\beta$-actin signals in the immunoblots were quantified by densitometry, the ratios of p21/Cdk or p21/ $\beta$-actin normalised to the level at time zero and plotted. The half-life of myc-p21 was calculated by a computer program. 
Cdk4 complex $\left(t_{1 / 2}: \sim 0.7-0.8\right.$ for mutants $v s 1.2 \mathrm{~h}$ for wild-type) when Cdk4 immunoprecipitates were examined (Figure 7B). In consonance, the stability of p21wt was greatest in Cdk2 immunoprecipitates $\left(t_{1 / 2}: 2.6 \mathrm{~h}\right)$, followed by $21 \mathrm{ED}\left(t_{1 / 2}: 1.0 \mathrm{~h}\right)$ and then $\mathrm{p} 21 \mathrm{TE}\left(t_{1 / 2}: 0.5 \mathrm{~h}\right)$ (Figure $\left.7 \mathrm{C}\right)$. These results strongly indicate that PCNA stabilises $\mathrm{p} 21$.

\section{DISCUSSION}

Cancer is caused by deregulation of the cell cycle, enabling tumour cells to proliferate without limits. However, many cancers retain the G1 checkpoint and respond to DNA damage by inducing/ activating the tumour suppressor $\mathrm{p} 53$, which then transactivates a number of downstream gene targets, including p21. In concordance with this understanding, our studies demonstrate that exposure of tumour cells to the platinum complex DAP results in G1 arrest, which is directly due to inhibition of G1-phase Cdk4/ cyclin D and Cdk2/cyclin E activities by $\mathrm{p} 21$. However, to our knowledge, our proteomic investigation is the first to demonstrate that the inhibition of G1-phase Cdk following DNA damage is associated with co-recruitment of p21 and trimeric PCNA to form a quaternary Cdk/cyclin/p21/PCNA complex. Moreover, our study reveals that PCNA does not inhibit Cdk activity but contributes indirectly by stabilising p21, the principle inhibitor of G1-phase Cdks, following DNA damage.

Levels of p21 are usually low in tumour cells to permit the unabated proliferation, but the levels increase following DNA damage to inhibit Cdk activity and induce cell-cycle arrest, as we have noted in this and other studies with platinum drugs cisplatin and DAP (Kuang et al, 2001; He et al, 2011). This increase in p21 is slow as it is mediated via transcriptional activation, and increases in p21 protein levels in cells or complexed to Cdk4/cyclin D and $\mathrm{CDk} 2 /$ cyclin $\mathrm{E}$ first become apparent at $6 \mathrm{~h}$, but do not become prominent until $18 \mathrm{~h}$ after initiating drug exposure (He et al, 2005). In the present study, we have demonstrated that this binding of p21 to Cdk/cyclin is associated with co-recruitment of PCNA, which interestingly also appears in the complex at $6 \mathrm{~h}$ and becomes prominent at $18 \mathrm{~h}$, and this is consistent with our finding that PCNA is co-recruited in a p21-dependent manner. It is noteworthy that PCNA is recruited into the Cdk4 complex before the Cdk2 complex, but this again is consistent with parallel recruitment of induced p21 first into the Cdk4 complex (Harper et al, 1993; He et al, 2005). Our studies, however, do not indicate whether p21 and PCNA recruitment into the $\mathrm{Cdk} /$ cyclin complex occurs sequentially or whether p21 binds first to PCNA. Given that p21 can interact directly with PCNA in the absence of Cdk/cyclin (Waga et al, 1994; Li et al, 1996), it is plausible that p21 and PCNA bind first before being recruited into G1-phase Cdk/cyclin to form the quaternary $\mathrm{Cdk}$ complex. On the other hand, our data support several reports that both wild-type p21 in the absence of PCNA (Harper et al, 1993) and engineered p21 to prevent PCNA binding (Prabhu et al, 1996; Cayrol et al, 1998; Rossig et al, 2001) still interact with $\mathrm{Cdk} /$ cyclin complex to inhibit kinase activity, and so the possibility that $\mathrm{p} 21$ recruitment may occur before PCNA into the inhibited complex cannot be excluded. Thus, further studies are needed to resolve the sequence of interaction between the Cdk/ cyclin, p21 and PCNA to form the quaternary complex.

The quaternary Cdk/cyclin/p21/PCNA complex has previously been described in control non-transformed human cells, such as lung and foreskin fibroblasts, but not in transformed cells where p21 and PCNA become excluded from the complex (Xiong et al, 1992, 1993b; Zhang et al, 1993). In our studies in control A2780 ovarian tumour cells, the most consistent interpretation of gel chromatography elution profiles and immunoprecipitation and immunoblot data is that the Cdk complex is present in a range of molecular sizes, which may well include the quaternary complex, but most likely at low levels. However, it appears from molecular size consideration that the $\sim 140 \mathrm{kDa}$ of the active Cdk complex in fraction 26 may not be attributable to the simple binary interaction between Cdk $(\sim 31-32 \mathrm{kDa})$ and the cognitive cyclin $\mathrm{D}(\sim 33-$ $34 \mathrm{kDa})$ or cyclin $\mathrm{E}(\sim 50 \mathrm{kDa})$. In this regard, similar-sized 120 and $160 \mathrm{kDa}$ Cdk complexes in control human T47D breast tumour cells and a $150 \mathrm{kDa}$ complex in 293 embryonic kidney cells have been reported to contain p21 (Musgrove et al, 1998; Poon and Hunter, 1998). Therefore, it is tempting to speculate the presence of p21 as a component of the $\sim 140 \mathrm{kDa}$ complex, but this is not supported by the finding in the present investigation that Cdk 4 and Cdk2 complexes immunoprecipitated from control A2780 tumour cells contained little or no detectable p21 or PCNA (Figure 4). Indeed, p21 is not required for the formation of the binary Cdk/ cyclin complex, as has been demonstrated in p21-deficient cells (Chytil et al, 2004). Thus, the presence of p21 at a significant level in the active $\sim 140 \mathrm{kDa}$ kinase complex from tumour cells in our study appears unlikely, nor necessary, but this does not exclude the possible presence of another protein within the active Cdk complex that evaded detection.

Our proteomic analysis revealed the presence of only Cdk, cyclin, p21 and PCNA in the inhibited G1-phase Cdk complex following DNA damage with DAP. This is surprising and contrary to expectations since PCNA can bind to a number of proteins, such as Topo I, Fen-1 and CAF-1 (Maga and Hubscher, 2003). However, it is highly plausible that binding with p21 prevents PCNA from interacting with other proteins in a mutually exclusive manner, as has been noted with DNA replication proteins Fen-1, RF-C and Pol- $\delta$ (Waga et al, 1994; Chen et al, 1996). Moreover, the $150-\mathrm{kDa}$ difference in the molecular size among the smaller, active and larger, inhibited Cdk complex following DNA damage can be explained in part by the presence of PCNA as a homotrimer in the present investigation. Although the binding of p21 to trimeric PCNA has been proposed previously, but under basal conditions or in cell-free systems using purified proteins, there is much disagreement in the literature over the stoichiometry. Some reports have indicated that only one molecule of p21 is bound to trimeric PCNA independent of Cdk/cyclin (Zhang et al, 1993; Xiong et al, 1993a; Waga et al, 1994), whereas others have suggested multiple p21 molecules associate with trimeric PCNA, with stoichiometry of 2-3 : 1 (Flores-Rozas et al, 1994; Li et al, 1996; Zheleva et al, 2000). The crystal structures of PCNA bound to $\mathrm{p} 21$ peptides have been described, but again a definitive understanding for the stoichiometry is lacking. Gulbis et al (1996) investigated binary interactions between p 21 and PCNA and proposed three peptides bound to trimeric PCNA within the crystal structure. On the other hand, Kontopidis et al (2005) have proposed a model for the quaternary $\mathrm{Cdk} /$ cyclin/p21/PCNA structure that only requires a single p21 molecule functioning as an adaptor protein between cyclin and a single PCNA of the homotrimer. This model, however, does not preclude the possibility of two additional molecules of p21 bound to the other two molecules of PCNA in the trimeric structure. Indeed, and in the absence of any other proteins associated with PCNA in our studies, the increase in the molecular size of the inhibited Cdk complex by $\sim 150 \mathrm{kDa}$ can be best described by recruitment of three molecules of p21 (molecular weight (MW) $\sim 21 \mathrm{kDa}$ each) bound to trimeric PCNA (MW $\sim 84-86 \mathrm{kDa}$ total).

Irrespective of the stoichiometry of proteins within the quaternary structure of the inhibited Cdk complex, our data in A2780 tumour cells reveal that PCNA is not essential for p21 to inhibit Cdk activity (see Figure $5 \mathrm{C}$ ), which is consistent with reports using cell-free systems (Adkins and Lumb, 2000). This, therefore, raises a major question as regards the function of PCNA within the Cdk complex. Since the cellular level of p21 is reduced following its mutation at specific amino-acid sites that prevent p21 binding to PCNA, it has been proposed that PCNA protects $\mathrm{p} 21$ 
from proteosomal degradation (Cayrol and Ducommun, 1998). In contrast, others have reported that PCNA binding promotes p21 degradation (Li et al, 2002; Abbas et al, 2008). Moreover, these reports did not examine the stability of p21 within the Cdk complex, and to the best of our knowledge such information has also not been reported by others. Our study, on the other hand, provides unequivocal evidence that PCNA stabilises p21 not only in tumour cells, but specifically within Cdk4 and Cdk2 complexes, which likely explains the robustness of Cdk inhibition and G1 arrest by p21. This may also explain the reported correlation between robust checkpoint response and drug sensitivity with platinum antitumour drugs (Vekris et al, 2004) and the reported abolishment of apoptosis in the presence of p21PCNA that cannot bind to PCNA (Chopin et al, 2004).

In summary, we have demonstrated that DNA damage by Pt-based antitumour agents induces p21-dependent inhibition of G1-phase Cdk4/cyclin D and Cdk2/cyclin E activity that is associated with an $\sim 150 \mathrm{kDa}$ increase in the molecular size of the Cdk complex. This large shift in size is due to recruitment of trimeric PCNA, likely bound to three molecules of p21 to form the $\mathrm{Cdk} /$ cyclin/p21/PCNA quaternary complex as a consequence of DNA damage response. Our data indicate that PCNA is not essential for inhibiting Cdk activity, but is required to stabilise and, thereby, prolong the inhibitory activity of p21 within the Cdk complex.

\section{ACKNOWLEDGEMENTS}

The research was supported by the US Public Health Service NCI grants CA127263 and CA160687 to ZHS and the Cancer Center Support Grant CA16672 to MD Anderson Cancer Center, and in part by the Megan McBride Franz Endowed Research Fund.

\section{CONFLICT OF INTEREST}

The authors declare no conflict of interest.

\section{REFERENCES}

Abbas T, Sivaprasad U, Terai K, Amador V, Pagano M, Dutta A (2008) PCNA-dependent regulation of p21 ubiquitylation and degradation via the CRL4Cdt2 ubiquitin ligase complex. Genes Dev 22(18): 2496-2506.

Adkins JN, Lumb KJ (2000) Stoichiometry of cyclin A-cyclin-dependent kinase 2 inhibition by p21Cip1/Waf1. Biochemistry 39(45): 13925-13930.

Cayrol C, Ducommun B (1998) Interaction with cyclin-dependent kinases and PCNA modulates proteasome-dependent degradation of $\mathrm{p} 21$. Oncogene 17(19): 2437-2444.

Cayrol C, Knibiehler M, Ducommun B (1998) p21 binding to PCNA causes G1 and G2 cell cycle arrest in p53-deficient cells. Oncogene 16(3): 311-320.

Chen U, Chen S, Saha P, Dutta A (1996) p21Cip1/Waf1 disrupts the recruitment of human Fen1 by proliferating-cell nuclear antigen into the DNA replication complex. Proc Natl Acad Sci USA 93(21): 11597-11602.

Chopin V, Toillon RA, Jouy N, Le B,X (2004) P21(WAF1/CIP1) is dispensable for G1 arrest, but indispensable for apoptosis induced by sodium butyrate in MCF-7 breast cancer cells. Oncogene 23(1): 21-29.

Chytil A, Waltner-Law M, West R, Friedman D, Aakre M, Barker D, Law B (2004) Construction of a cyclin D1-Cdk2 fusion protein to model the biological functions of cyclin D1-Cdk2 complexes. J Biol Chem 279(46): 47688-47698.

Coqueret O (2003) New roles for p21 and p27 cell-cycle inhibitors: a function for each cell compartment? Trends Cell Biol 13(2): 65-70.

Davis MT, Lee TD (1998) Rapid protein identification using a microscale electrospray LC/MS system on an ion trap mass spectrometer. J Am Soc Mass Spectrom 9(3): 194-201.
Deng C, Zhang P, Harper JW, Elledge SJ, Leder P (1995) Mice lacking p21CIP1/WAF1 undergo normal development, but are defective in G1 checkpoint control. Cell 82(4): 675-684.

Estanyol JM, Jaumot M, Casanovas O, Rodriguez-Vilarrupla A, Agell N, Bachs O (1999) The protein SET regulates the inhibitory effect of p21(Cip1) on cyclin E-cyclin-dependent kinase 2 activity. J Biol Chem 274(46): 33161-33165.

Flores-Rozas H, Kelman Z, Dean FB, Pan ZQ, Harper JW, Elledge SJ, O’Donnell M, Hurwitz J (1994) Cdk-interacting protein 1 directly binds with proliferating cell nuclear antigen and inhibits DNA replication catalyzed by the DNA polymerase delta holoenzyme. Proc Natl Acad Sci USA 91(18): 8655-8659.

Gulbis JM, Kelman Z, Hurwitz J, O’Donnell M, Kuriyan J (1996) Structure of the C-terminal region of $\mathrm{p} 21$ (WAF1/CIP1) complexed with human PCNA. Cell 87(2): 297-306.

Harper JW, Adami GR, Wei N, Keyomarsi K, Elledge SJ (1993) The p21 Cdk-interacting protein Cip1 is a potent inhibitor of G1 cyclin-dependent kinases. Cell 75(4): 805-816.

Harper JW, Elledge SJ, Keyomarsi K, Dynlacht B, Tsai LH, Zhang P, Dobrowolski S, Bai C, Connell-Crowley L, Swindell E (1995) Inhibition of cyclin-dependent kinases by p21. Mol Biol Cell 6(4): 387-400.

He G, Kuang J, Huang Z, Koomen J, Kobayashi R, Khokhar AR, Siddik ZH (2006) Upregulation of p27 and its inhibition of CDK2/cyclin E activity following DNA damage by a novel platinum agent are dependent on the expression of p21. Br J Cancer 95(11): 1514-1524.

He G, Kuang J, Khokhar AR, Siddik ZH (2011) The impact of S- and G2-checkpoint response on the fidelity of G1-arrest by cisplatin and its comparison to a non-cross-resistant platinum(IV) analog. Gynecol Oncol 122(2): 402-409.

He G, Siddik ZH, Huang Z, Wang R, Koomen J, Kobayashi R, Khokhar AR, Kuang J (2005) Induction of p21 by p53 following DNA damage inhibits both Cdk4 and Cdk2 activities. Oncogene 24(18): 2929-2943.

Hengst L, Gopfert U, Lashuel HA, Reed SI (1998) Complete inhibition of Cdk/cyclin by one molecule of p21(Cip1). Genes Dev 12(24): 3882-3888.

Hermeking H, Funk JO, Reichert M, Ellwart JW, Eick D (1995) Abrogation of p53-induced cell cycle arrest by c-Myc: evidence for an inhibitor of p21WAF1/CIP1/SDI1. Oncogene 11(7): 1409-1415.

Iliakis G, Wang Y, Guan J, Wang H (2003) DNA damage checkpoint control in cells exposed to ionizing radiation. Oncogene 22(37): 5834-5847.

Jonsson ZO, Podust VN, Podust LM, Hubscher U (1995) Tyrosine 114 is essential for the trimeric structure and the functional activities of human proliferating cell nuclear antigen. EMBO J 14(22): 5745-5751.

Khokhar AR, al Baker S, Shamsuddin S, Siddik ZH (1997) Chemical and biological studies on a series of novel (trans-(1R,2R)-, trans-(1S,2S)-, and cis-1,2-diaminocyclohexane)platinum(IV) carboxylate complexes. J Med Chem 40(1): 112-116.

Kontopidis G, Wu SY, Zheleva DI, Taylor P, McInnes C, Lane DP, Fischer PM, Walkinshaw MD (2005) Structural and biochemical studies of human proliferating cell nuclear antigen complexes provide a rationale for cyclin association and inhibitor design. Proc Natl Acad Sci USA 102(6): 1871-1876.

Koomen JM, Li D, Xiao LC, Liu TC, Coombes KR, Abbruzzese J, Kobayashi R (2005) Direct tandem mass spectrometry reveals limitations in protein profiling experiments for plasma biomarker discovery. J Proteome Res 4(3): 972-981.

Koundrioukoff S, Jonsson ZO, Hasan S, de Jong RN, van der Vliet PC, Hottiger MO, Hubscher U (2000) A direct interaction between proliferating cell nuclear antigen (PCNA) and Cdk2 targets PCNA-interacting proteins for phosphorylation. J Biol Chem 275(30): 22882-22887.

Kuang J, He G, Huang Z, Khokhar AR, Siddik ZH (2001) Bimodal effects of 1R,2R-diaminocyclohexane(trans-diacetato)(dichloro)platinum(IV) on cell cycle checkpoints. Clin Cancer Res 7(11): 3629-3639.

LaBaer J, Garrett MD, Stevenson LF, Slingerland JM, Sandhu C, Chou HS, Fattaey A, Harlow E (1997) New functional activities for the p21 family of CDK inhibitors. Genes Dev 11(7): 847-862.

Li R, Hannon GJ, Beach D, Stillman B (1996) Subcellular distribution of p21 and PCNA in normal and repair-deficient cells following DNA damage. Curr Biol 6(2): 189-199.

Li Y, Dowbenko D, Lasky LA (2002) AKT/PKB phosphorylation of p21Cip/ WAF1 enhances protein stability of p21Cip/WAF1 and promotes cell survival. J Biol Chem 277(13): 11352-11361.

Lukas J, Bartkova J, Welcker M, Petersen OW, Peters G, Strauss M, Bartek J (1995) Cyclin D2 is a moderately oscillating nucleoprotein required for G1 phase progression in specific cell types. Oncogene 10(11): 2125-2134. 
Maga G, Hubscher U (2003) Proliferating cell nuclear antigen (PCNA): a dancer with many partners. J Cell Sci 116(Pt 15): 3051-3060.

Malumbres M, Sotillo R, Santamaria D, Galan J, Cerezo A, Ortega S, Dubus P, Barbacid M (2004) Mammalian cells cycle without the D-type cyclin-dependent kinases Cdk4 and Cdk6. Cell 118(4): 493-504.

Musgrove EA, Swarbrick A, Lee CS, Cornish AL, Sutherland RL (1998) Mechanisms of cyclin-dependent kinase inactivation by progestins. Mol Cell Biol 18(4): 1812-1825.

Pietenpol JA, Stewart ZA (2002) Cell cycle checkpoint signaling: cell cycle arrest versus apoptosis. Toxicology 181-182: 475-481.

Poon RY, Hunter T (1998) Expression of a novel form of p21Cip1/Waf1 in UV-irradiated and transformed cells. Oncogene 16(10): 1333-1343.

Prabhu NS, Blagosklonny MV, Zeng YX, Wu GS, Waldman T, el Deiry WS (1996) Suppression of cancer cell growth by adenovirus expressing p21(WAF1/CIP1) deficient in PCNA interaction. Clin Cancer Res 2(7): 1221-1229.

Rossig L, Jadidi AS, Urbich C, Badorff C, Zeiher AM, Dimmeler S (2001) Aktdependent phosphorylation of p21(Cip1) regulates PCNA binding and proliferation of endothelial cells. Mol Cell Biol 21(16): 5644-5657.

Samuel T, Weber HO, Funk JO (2002) Linking DNA damage to cell cycle checkpoints. Cell Cycle 1(3): 162-168.

Schneider C, Newman RA, Sutherland DR, Asser U, Greaves MF (1982) A one-step purification of membrane proteins using a high efficiency immunomatrix. J Biol Chem 257(18): 10766-10769.

Scott MT, Morrice N, Ball KL (2000) Reversible phosphorylation at the C-terminal regulatory domain of $\mathrm{p} 21$ (Waf1/Cip1) modulates proliferating cell nuclear antigen binding. J Biol Chem 275(15): 11529-11537.

Sherr CJ, Roberts JM (1999) CDK inhibitors: positive and negative regulators of G1-phase progression. Genes Dev 13(12): 1501-1512.

Shevchenko A, Wilm M, Vorm O, Mann M (1996) Mass spectrometric sequencing of proteins silver-stained polyacrylamide gels. Anal Chem 68(5): $850-858$

Siddik ZH (2003) Cisplatin: mode of cytotoxic action and molecular basis of resistance. Oncogene 22(47): 7265-7279.
Siddik ZH, Mims B, Lozano G, Thai G (1998) Independent pathways of p53 induction by cisplatin and X-rays in a cisplatin-resistant ovarian tumor cell line. Cancer Res 58(4): 698-703.

Vekris A, Meynard D, Haaz MC, Bayssas M, Bonnet J, Robert J (2004) Molecular determinants of the cytotoxicity of platinum compounds: the contribution of in silico research. Cancer Res 64(1): 356-362.

Vestal M, Juhasz P (1998) Resolution and mass accuracy in matrix-assisted laser desorption ionization time-of-flight. J Am Soc Mass Spectrom 9: 892-911.

Waga S, Hannon GJ, Beach D, Stillman B (1994) The p21 inhibitor of cyclindependent kinases controls DNA replication by interaction with PCNA. Nature 369(6481): 574-578.

Xiong Y, Hannon GJ, Zhang H, Casso D, Kobayashi R, Beach D (1993a) p21 is a universal inhibitor of cyclin kinases. Nature 366(6456): 701-704.

Xiong Y, Zhang H, Beach D (1992) D type cyclins associate with multiple protein kinases and the DNA replication and repair factor PCNA. Cell 71(3): 505-514.

Xiong Y, Zhang H, Beach D (1993b) Subunit rearrangement of the cyclindependent kinases is associated with cellular transformation. Genes Dev 7(8): 1572-1583.

Zhang H, Hannon GJ, Beach D (1994) p21-containing cyclin kinases exist in both active and inactive states. Genes Dev 8(15): 1750-1758.

Zhang H, Xiong Y, Beach D (1993) Proliferating cell nuclear antigen and p21 are components of multiple cell cycle kinase complexes. Mol Biol Cell 4(9): 897-906.

Zheleva DI, Zhelev NZ, Fischer PM, Duff SV, Warbrick E, Blake DG, Lane DP (2000) A quantitative study of the in vitro binding of the C-terminal domain of p21 to PCNA: affinity, stoichiometry, and thermodynamics. Biochemistry 39(25): 7388-7397.

This work is published under the standard license to publish agreement. After 12 months the work will become freely available and the license terms will switch to a Creative Commons AttributionNonCommercial-Share Alike 3.0 Unported License. 